\title{
IAMM: A Maturity Model for Measuring Industrial Analytics Capabilities in Large-scale Manufacturing Facilities
}

\author{
Peter O’Donovan, Ken Bruton, and Dominic T.J. O’Sullivan \\ School of Engineering, University College Cork, Ireland \\ peter_odonovan@umail.ucc.ie
}

\begin{abstract}
Industrial big data analytics is an emerging multidisciplinary field, which incorporates aspects of engineering, statistics and computing, to produce data-driven insights that can enhance operational efficiencies, and produce knowledgebased competitive advantages. Developing industrial big data analytics capabilities is an ongoing process, whereby facilities continuously refine collaborations, workflows and processes to improve operational insights. Such activities should be guided by formal measurement methods, to strategically identify areas for improvement, demonstrate the impact of analytics initiatives, as well as deriving benchmarks across facilities and departments. This research presents a formal multi-dimensional maturity model for approximating industrial analytics capabilities, and demonstrates the model's ability to assess the impact of an initiative undertaken in a real-world facility.
\end{abstract}

\section{INTRODUCTION}

Modern manufacturing facilities are becoming increasingly more data-intensive. Such environments support the transmission, sharing and analysis of information across pervasive networks to produce data-driven manufacturing intelligence (Chand and Davis 2010; Davis et al. 2012; Lee, $\mathrm{Kao}$, and Yang 2014). This intelligence may provide many benefits, including improvements in operational efficiency, process innovation, and environmental impact, to name a few (Fosso Wamba et al. 2015; Hazen et al. 2014). To realize these benefits industrial information systems must be capable of storing and processing exponentially growing datasets (i.e. Big Data), while supporting predictive and scenario analytics to inform real-time decision-making (Fosso Wamba et al. 2015; Kumar et al. 2014; Lee et al. 2013; McKinsey 2011; Philip Chen and Zhang 2014; Verabaquero, Colomo-palacios, and Molloy 2014). Greater data production may be attributed to increased sensing

Peter O'Donovan et al. This is an open-access article distributed under the terms of the Creative Commons Attribution 3.0 United States License, which permits unrestricted use, distribution, and reproduction in any medium, provided the original author and source are credited. capabilities, and persistence of higher resolution operational data. These sensing technologies encompass both legacy automation networks and emerging paradigms (e.g. Internet of Things and Cyber Physical Systems) (Davis et al. 2012; Lee, Bagheri, and Kao 2015; Wright 2014). The data collected from these networks may be analyzed and modeled to produce data-driving insights. These technologies and processes are becoming synonymous with industrial big data analytics, which incorporates aspects of big data analytics, automation, control and engineering.

Given the contemporary and multidisciplinary nature of industrial big data analytics, measuring current industrial analytics capabilities can be difficult. Such measurements could identify areas for strategic improvement, while also illustrating the impact of historical initiatives. In other business domains, capability assessment has been achieved using maturity models. While maturity models exist for aspects of industrial analytics (e.g. big data), they do not capture the dimensions or details needed to support capability assessment of the industrial domain. Thus, this research presents the development and application of an industrial analytics maturity model to approximate capabilities across numerous operating dimensions.

\section{RELATED WORK}

Given the contemporary, diverse and multidisciplinary nature of industrial analytics, determining current capabilities and developing strategic roadmaps may prove difficult. Many of these challenges are addressed in other domains using maturity models, which approximate capabilities and highlight strengths and weaknesses in a particular area (Ayca et al. 2016). Examples of such domains include Information Technology, Software Engineering, Data Management, and Business Process Management, to name a few (Koehler, Woodtly, and Hofstetter 2015; Ngai et al. 2013; Ofner, Otto, and Österle 2015; Oliva 2016; Torrecilla-Salinas et al. 2016). While there are currently no maturity models focused specifically on industrial analytics, several models exist for measuring Big Data and Internet of Things (Halper and Krishnan 2014; 
IBM 2016; IDC 2016; Infotech 2016; Knowledgent 2016; Potter 2014; Radcliffe 2014) capabilities. These models are predominantly of commercial origin with insufficient documentation to support assessment, while their methodological and theoretical foundations are unclear.

Maturity models reflect aspects of reality to classify capabilities (Kohlegger, Maier, and Thalmann 2009), which may be used for comparison and benchmarking (Rajterič 2010). Such models typically comprise dimensions and levels. Levels are ordinal labels that signify stages of maturity, while dimensions represent specific capabilities from the domain of interest. These dimensions may be further populated (e.g. technologies and processes) to facilitate deeper capability assessments (Lahrmann and Marx 2010). The contents of each dimension may by derived using qualitative research methods, including case studies, focus groups and the Delphi method (Lahrmann et al. 2011). Given the potential sophistication of some models, models are generally limited to measuring a particular aspect of a domain (Rajterič 2010), although multiple models can be aligned to facilitate broader assessments. However, aligning multiple models can be challenging when different dimensions and levels exist (Kohlegger, Maier, and Thalmann 2009).

The common criticisms associated with maturity models include insufficient accuracy, poor documentation, inadequate theory, and design bias (Dinter 2012; Lahrmann et al. 2011; Lahrmann and Marx 2010) - Dinter concluded maturity models cannot mitigate biases, even when empirical methods exist (Dinter 2012), while Lahrmann et al. (2010) reported many models are poorly documented and theoretically weak (Lahrmann and Marx 2010). There are three well-established development methodologies found in literature - De Bruin et al. (De Bruin et al. 2005), Becker et al. (Becker, Knackstedt, and Pöppelbuß 2009) and Mettler (Mettler 2009). These methodologies describe iterative approaches that facilitate continuous model improvement (Dinter 2012; Poeppelbuss et al. 2011). Therefore, maturity models must be refined and improved to reflect the nuances of the domain.

Given the contemporary and multidisciplinary nature of industrial analytics, determining current capabilities and creating strategic roadmaps can be challenging. Many of these challenges are addressed in other domains using maturity models (Koehler, Woodtly, and Hofstetter 2015; Lahrmann et al. 2011; Ngai et al. 2013; Ofner, Otto, and Österle 2015; Oliva 2016; Torrecilla-Salinas et al. 2016). Although closely related maturity models exist for mainstream Big Data and Internet of Things (Halper and Krishnan 2014; IBM 2016; IDC 2016; Infotech 2016; Knowledgent 2016; Potter 2014; Radcliffe 2014), these models do not possess the depth needed to measure industrial analytics capabilities.

\section{RESEARCH Methodology}

This research employs an action research approach to design and test a maturity model for measuring industrial analytics capabilities (De Villiers 2005). This approach was chosen given its ability to link theory and practice when investigating real-world challenges (Abdel-Fattah 2015). This research presents a maturity model to address measurement, comparison and benchmarking challenges pertaining to industrial analytics capabilities. The maturity model development process of De Bruin et al. (De Bruin et al. 2005) was used to construct the Industrial Analytics Maturity Model (IAMM). This process consisted of six sequential phases (Figure 1), with each phase containing criteria that characterized the model.

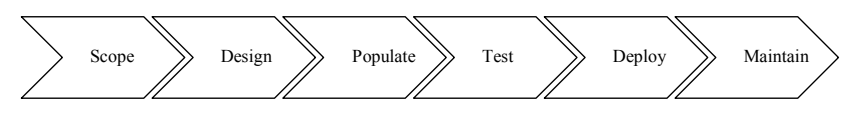

Figure 1. Model development phases (De Bruin et al. 2005)

\subsection{Model Development}

\subsubsection{Phase 1 - Scope}

The scope phase defines model boundaries using predefined criteria (Table 1). A model's focus can be domain-specific or generic. Generic models are those that may be applied across different domains (e.g. quality), while domainspecific models are coupled to a particular scenario (e.g. software development). Those that have an implied interest in the model's creation are known as development stakeholders. These stakeholders can inform the model's development, or benefit from its application. Examples of stakeholders may include academia, practitioners, and government entities.

The IAMM was classified as domain-specific given its focus on industrial analytics, with academic researchers and industry practitioners identified as development stakeholders. These stakeholders were deemed relevant given the model enables them to (a) illustrate current capabilities, (b) highlight areas for improvement, and (3) measure the impact of initiatives. These choices are highlighted in the selection column (Table 1).

\begin{tabular}{l|l|c}
\hline Criteria & Options & Selection \\
\hline Focus of Model & Domain Specific & $\square$ \\
\hline & General & \\
\hline Stakeholders & Academia & $\square$ \\
\hline & Practitioners & $\square$ \\
\hline & Government & \\
\hline & Combination & $\square$ \\
\hline
\end{tabular}

Table 1. Scope criteria selection for IAMM 


\subsubsection{Phase 2 - Design}

The design phase defines model architecture and application using predefined criteria (Table 2). These criteria provide a deeper understanding of (1) who will use the model, (2) why they need the model, and (3) how they can apply the model. These design details must manage the trade-off between domain accuracy and model simplicity. While simple models may not reflect the nuances of the domain, complex models may create user adoption challenges (e.g. timeconsuming assessment process).

The IAMM's audience was classified as internal executives and management, given they are responsible for improving in-house industrial analytics capabilities. A self-assessment method controlled by staff members was chosen to measure analytics capabilities, which would be driven by internal roadmaps and objectives (e.g. smart manufacturing). These assessments should consider multiple perspectives and dimensions (e.g. automation and mainstream technology) to evaluate maturity.

\begin{tabular}{l|l|c}
\hline Criteria & Options & Selection \\
\hline Audience & Internal Executives and \\
& Management & $\square$ \\
\hline & External Auditors and Partners & \\
\hline Method & Self-Assessment & $\square$ \\
\hline & Third Party Associated & \\
\hline & Certified Practitioner & $\square$ \\
\hline Driver & Internal Requirement & \\
\hline & External Requirement & \\
\hline Respondents & Management & $\square$ \\
\hline & Staff & \\
\hline Application & Business Partners & Single Entity / Single Region \\
\hline & Multiple Entities / Single Region & \\
\hline & $\begin{array}{l}\text { Multiple Entities / Multiple } \\
\text { Regions }\end{array}$ & $\square$ \\
\hline
\end{tabular}

Table 2. Design criteria selection of IAMM

A maturity model structure and application may take two forms. First, models may employ a multi-level approach. These models adhere to the continuous maturity principle, where multiple dimensions of the model may assert different maturity levels. This approach is useful for modeling multifaceted domains, and highlighting strengths and weaknesses. Second, models may also employ a singlelevel approach. These models adhere to the staged maturity principle, which use a single label to classify maturity. This approach may suit scenarios where natural linear progressions exist (e.g. beginner to advanced).

The IAMM's architecture follows a multi-level approach given multiple disciplines exist in the industrial analytics domain (Table 3). This approach also provides the flexibility needed to align maturity assessment with operational goals and objectives (e.g. not all facilities may wish to enhance embedded analytics).

\begin{tabular}{l|l|l}
\hline Dimension & Levels & Rationale \\
\hline $\begin{array}{l}\text { Open } \\
\text { Standards }\end{array}$ & 10 & $\begin{array}{l}\text { Standards-based technologies } \\
\text { and protocols are needed to } \\
\text { promote interoperability between } \\
\text { different stages in the industrial } \\
\text { analytics lifecycle. }\end{array}$ \\
\hline $\begin{array}{l}\text { Operation } \\
\text { Technology }\end{array}$ & 10 & $\begin{array}{l}\text { Operation Technology must } \\
\text { support the systems and } \\
\text { processes that facilitate the } \\
\text { acquisition of industrial data in } \\
\text { the factory. }\end{array}$ \\
\hline $\begin{array}{l}\text { Information } \\
\text { Technology }\end{array}$ & 10 & $\begin{array}{l}\text { Information Technology must } \\
\text { provide the infrastructure and } \\
\text { technologies needed to support } \\
\text { the transmission and processing } \\
\text { of data between different areas of } \\
\text { the industrial analytics lifecycle. }\end{array}$ \\
\hline Data Analytics & 10 & $\begin{array}{l}\text { Data Analytics must possess the } \\
\text { knowledge and skills necessary } \\
\text { to model engineering problems } \\
\text { that can be deployed in factory } \\
\text { operations. }\end{array}$ \\
\hline $\begin{array}{l}\text { Embedded } \\
\text { Analytics }\end{array}$ & 10 & $\begin{array}{l}\text { Embedded Analytics must } \\
\text { facilitate the deployment of data- } \\
\text { driven models in the factory to } \\
\text { affect real-time decision-making } \\
\text { across operations. }\end{array}$ \\
\hline
\end{tabular}

Table 3. IAMM architecture and dimensions

\subsubsection{Phase 3 - Populate}

The populate phase defines model components and subcomponents, which relate to different aspects of the domain being assessed. Such components may be identified using formal methods, such as literature reviews, stakeholder interviews, surveys, and case studies, to name a few. Given multi-dimensional industrial analytics maturity models do not exist in literature, the IAMM was populated (Figure 2) using knowledge derived from previous research efforts (Donovan et al. 2015; O'Donovan, Bruton, and O'Sullivan 2016). The IAMM structure contains dimension components (green) and capability subcomponents (blue). These subcomponents describe processes and technologies that derive maturity for (1) Open Standards, (2) Operation Technology, (3) Information Technology, (4) Data Analytics, and (5) Embedded Analytics. 


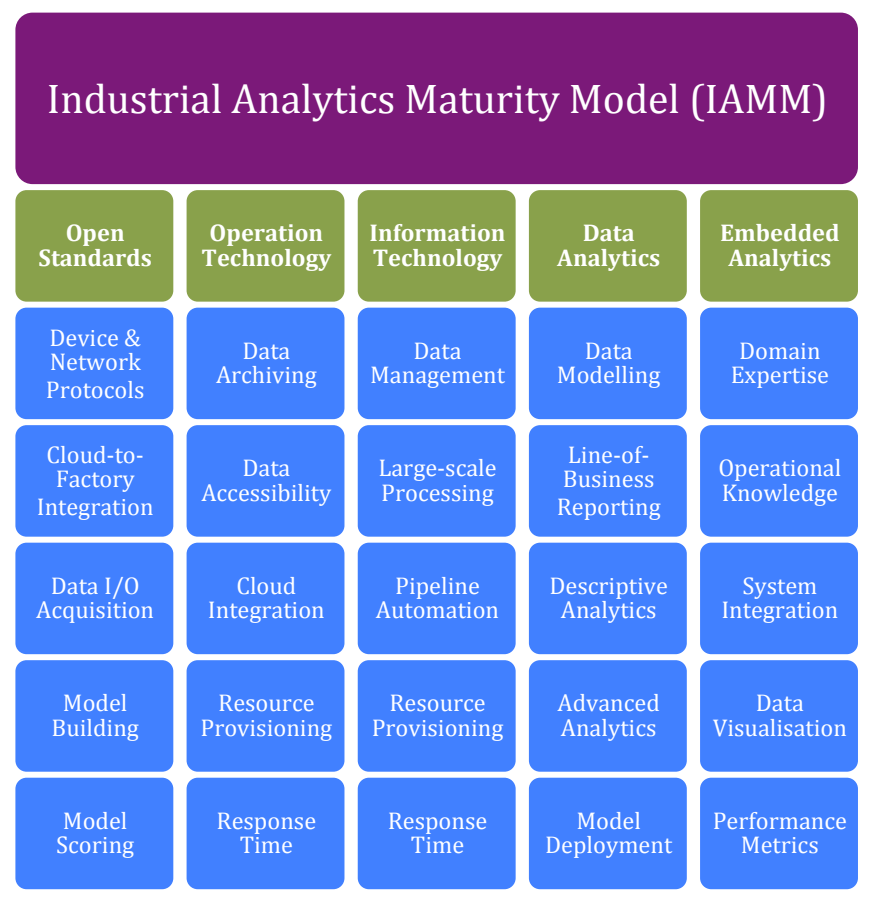

Figure 2. Industrial analytics maturity model architecture

Each dimension's subcomponents were assessed using hypothesis statements (Table 4) to determine approximate truth. Such statements enable practitioners to approximate maturity using an agreement scale (Yes=2, Partially=1, or $\mathrm{No}=0$ ), with dimension maturity derived from the average subcomponent score.

\begin{tabular}{l|l|l}
\hline Code & Component & Hypothesis Statements \\
\hline D1.1 & $\begin{array}{l}\text { Devices \& } \\
\text { Network } \\
\text { Protocols }\end{array}$ & $\begin{array}{l}\text { Devices and instrumentation in the } \\
\text { factory are accessed using open } \\
\text { technology standards. }\end{array}$ \\
\hline D1.2 & $\begin{array}{l}\text { Cloud-to- } \\
\text { Factory } \\
\text { Integration }\end{array}$ & $\begin{array}{l}\text { The factory floor is connected with } \\
\text { cloud platforms using open technology } \\
\text { standards. }\end{array}$ \\
\hline D1.3 & $\begin{array}{l}\text { Data I/O } \\
\text { Acquisition }\end{array}$ & $\begin{array}{l}\text { Archived operational data can be } \\
\text { queried using standard I/O interfaces. }\end{array}$ \\
\hline D1.4 & $\begin{array}{l}\text { Model } \\
\text { Building }\end{array}$ & $\begin{array}{l}\text { Data-driven models are interoperable } \\
\text { with other software, platforms and } \\
\text { engines. }\end{array}$ \\
\hline D1.5 & $\begin{array}{l}\text { Model } \\
\text { Scoring }\end{array}$ & $\begin{array}{l}\text { Production-ready data-driven models } \\
\text { are accessed and scored using standard } \\
\text { protocols. }\end{array}$ \\
\hline D2.1 & $\begin{array}{l}\text { Data } \\
\text { Archiving }\end{array}$ & $\begin{array}{l}\text { All data points and measurements in the } \\
\text { factory are archived in a central } \\
\text { location. }\end{array}$ \\
\hline D2.2 & $\begin{array}{l}\text { Data } \\
\text { Accessibility }\end{array}$ & $\begin{array}{l}\text { Archived data is labeled, catalogued, } \\
\text { identifiable, and directly accessible. }\end{array}$ \\
\hline D2.3 & $\begin{array}{l}\text { Cloud } \\
\text { Integration }\end{array}$ & $\begin{array}{l}\text { Real-time operations utilize cloud } \\
\text { computing for large-scale data storage, } \\
\text { processing or analysis. }\end{array}$ \\
\hline D2.4 & $\begin{array}{l}\text { Resource } \\
\text { Provisioning }\end{array}$ & $\begin{array}{l}\text { New compute or technical resources are } \\
\text { provisioned to support analytics efforts. }\end{array}$ \\
\hline D2.5 & $\begin{array}{l}\text { Response } \\
\text { Time }\end{array}$ & $\begin{array}{l}\text { Basic provisioning and support requests } \\
\text { relating are fulfilled in 24 to 48 hours. }\end{array}$ \\
\hline
\end{tabular}

\begin{tabular}{|c|c|c|}
\hline D3.1 & $\begin{array}{l}\text { Data } \\
\text { Management }\end{array}$ & $\begin{array}{l}\text { Governance policies exist for } \\
\text { cataloguing, storing, processing, and } \\
\text { identifying data sources. }\end{array}$ \\
\hline D3.2 & $\begin{array}{l}\text { Large-scale } \\
\text { Processing }\end{array}$ & $\begin{array}{l}\text { Scalable and robust architectures exist } \\
\text { to support exponential increases in data } \\
\text { throughput. }\end{array}$ \\
\hline D3.3 & $\begin{array}{l}\text { Pipeline } \\
\text { Automation }\end{array}$ & $\begin{array}{l}\text { Manually data processing and cleaning } \\
\text { routines have been automated using } \\
\text { workflow pipelines. }\end{array}$ \\
\hline D3.4 & $\begin{array}{l}\text { Resource } \\
\text { Provisioning }\end{array}$ & $\begin{array}{l}\text { New compute or technical resources are } \\
\text { provisioned to support analytics efforts. }\end{array}$ \\
\hline D3.5 & $\begin{array}{l}\text { Response } \\
\text { Time }\end{array}$ & $\begin{array}{l}\text { Basic provisioning and support requests } \\
\text { relating are fulfilled in } 24 \text { to } 48 \text { hours. }\end{array}$ \\
\hline D4.1 & $\begin{array}{l}\text { Data } \\
\text { Modeling }\end{array}$ & $\begin{array}{l}\text { Data transformation, wrangling and } \\
\text { preparation activities are undertaken } \\
\text { using our own statistical tools and } \\
\text { libraries. }\end{array}$ \\
\hline D4.2 & $\begin{array}{l}\text { Line-of- } \\
\text { Business } \\
\text { Reporting }\end{array}$ & $\begin{array}{l}\text { Performance reporting and analysis is } \\
\text { undertaken using productivity tools } \\
\text { such as MS Excel. }\end{array}$ \\
\hline D4.3 & $\begin{array}{l}\text { Descriptive } \\
\text { Analytics }\end{array}$ & $\begin{array}{l}\text { Basic data relationships and patterns are } \\
\text { identified in each month using } \\
\text { statistical software packages. }\end{array}$ \\
\hline D4.4 & $\begin{array}{l}\text { Advanced } \\
\text { Analytics }\end{array}$ & $\begin{array}{l}\text { Predictive data-driven models are } \\
\text { regularly built to inform decision- } \\
\text { making. }\end{array}$ \\
\hline D4.5 & $\begin{array}{l}\text { Model } \\
\text { Deployment }\end{array}$ & $\begin{array}{l}\text { Accurate data-driven models are always } \\
\text { deployed to provide end-users with } \\
\text { access to the new knowledge. }\end{array}$ \\
\hline D5.1 & $\begin{array}{l}\text { Domain } \\
\text { Expertise }\end{array}$ & $\begin{array}{l}\text { Subject matter experts guide analytics } \\
\text { investigations and questions relating to } \\
\text { factory operations. }\end{array}$ \\
\hline D5.2 & $\begin{array}{l}\text { Operational } \\
\text { Knowledge }\end{array}$ & $\begin{array}{l}\text { Subject matter experts informing } \\
\text { analytics efforts always possess an } \\
\text { intimate knowledge of the process } \\
\text { being investigated. }\end{array}$ \\
\hline D5.3 & $\begin{array}{l}\text { System } \\
\text { Integration }\end{array}$ & $\begin{array}{l}\text { Production-ready models are always } \\
\text { integrated in the factory to positively } \\
\text { impact operations and decision-making. }\end{array}$ \\
\hline D5.4 & $\begin{array}{l}\text { Data } \\
\text { Visualization }\end{array}$ & $\begin{array}{l}\text { Knowledge contained in models is } \\
\text { presented to end-users in a manner that } \\
\text { simplifies decision-making. }\end{array}$ \\
\hline D5.5 & $\begin{array}{l}\text { Performance } \\
\text { Metrics }\end{array}$ & $\begin{array}{l}\text { Top-line metrics are used extensively in } \\
\text { embedded analytics applications } \\
\text { throughout the factory. }\end{array}$ \\
\hline
\end{tabular}

Table 4. Industrial analytics maturity model assessment

\subsubsection{Phases 4 to 6 - Test, Deploy and Maintain}

These three phases define feedback mechanisms and model improvement protocols. While the test phase determines if the model's architecture correctly represents the target domain, deploy and maintain phases focus on applying and refining the model. Given the IAMM's design, structure and completeness originated from real-world requirements and analysis activities, further testing the model's alignment with the domain was not deemed necessary (O'Donovan, Bruton, and O'Sullivan 2016). This enabled the deployment of the IAMM to a large-scale manufacturing facility, where 
it was used to measure the impact of an energy-focused industrial analytics initiative.

\subsection{Model Validity}

Potential threats to the IAMM's validity may be classified as those generally associated with maturity models, and those stemming from model-specific design. Some of these threats are described in Table 5.

\begin{tabular}{|c|c|}
\hline Threat & Discussion \\
\hline Accuracy & $\begin{array}{l}\text { Given IAMM focuses on approximating industrial } \\
\text { analytics capabilities for comparison and } \\
\text { benchmarking, accuracy was not considered a major } \\
\text { threat. We consider assessment consistency across } \\
\text { longitudinal analysis as a greater threat. Such } \\
\text { challenges may be addressed by refining assessment } \\
\text { guidelines, but developing in-house assessment } \\
\text { policies and procedures are equally important. }\end{array}$ \\
\hline Scoring & $\begin{array}{l}\text { There is an inherent trade-off between model } \\
\text { granularity and usability. High-level models lack } \\
\text { sufficient detail to guide assessment, while low-level } \\
\text { models may come with significant overheads. } \\
\text { IAMM adopts somewhat of a hybrid perspective, } \\
\text { whereby a complete architecture guides assessment, } \\
\text { but simplified scoring facilitates easy adoption. } \\
\text { These trade-offs may be addressed in the future. }\end{array}$ \\
\hline Bias & $\begin{array}{l}\text { Maturity models are naturally subject to design bias. } \\
\text { Bias cannot be avoided completely given the level of } \\
\text { interpretation involved in model construction. To } \\
\text { mitigate direct researcher design bias, the IAMM } \\
\text { architecture was formed using multiple operational } \\
\text { perspectives acquired from the factory. Where user- } \\
\text { derived design biases exist, iterative refinement and } \\
\text { practitioner feedback will facilitate their dilution. }\end{array}$ \\
\hline Coverage & $\begin{array}{l}\text { Measuring capabilities across entire domains is } \\
\text { somewhat unrealistic. Hence, maturity models tend } \\
\text { to address specific aspects of a particular domain. } \\
\text { IAMM focuses on operational convergences } \\
\text { associated with industrial analytics capabilities. } \\
\text { During model design particular capability } \\
\text { components were filtered to ensure coherence, while } \\
\text { trying to preserve important capability } \\
\text { characteristics. Similarly to previous threats, gaps in } \\
\text { domain coverage can be addressed using iterative } \\
\text { model refinement and practitioner feedback. }\end{array}$ \\
\hline
\end{tabular}

Table 5. Summary of research validity threats

\section{RESUltS AND DisCUSSION}

This section describes the deployment and application of the IAMM to measure the impact of an energy-focused industrial analytics initiative in a large-scale manufacturing facility. The impact was determined using capability assessments recorded before and after the implementation of an industrial analytics architecture (O'Donovan, Bruton, and O'Sullivan 2016). This capability assessment was undertaken to demonstrate the application and usefulness of the IAMM as a means of measuring change, and highlighting operational strengths and weaknesses in the context of data-driven energy operations.

\subsection{Assessment Protocol}

Figure 3 illustrates the assessment protocol used to measure industrial analytics capabilities in this research. The figure shows actions undertaken by each researcher (i.e. three assessors) in the outer section (e.g. score, reason etc.), which were collaboratively synthesized to derive final capability levels. This enabled researchers to make their own assertions regarding capability changes, while knowing any individual bias would eventually be diluted. Table 6 summarizes each step in this assessment protocol.

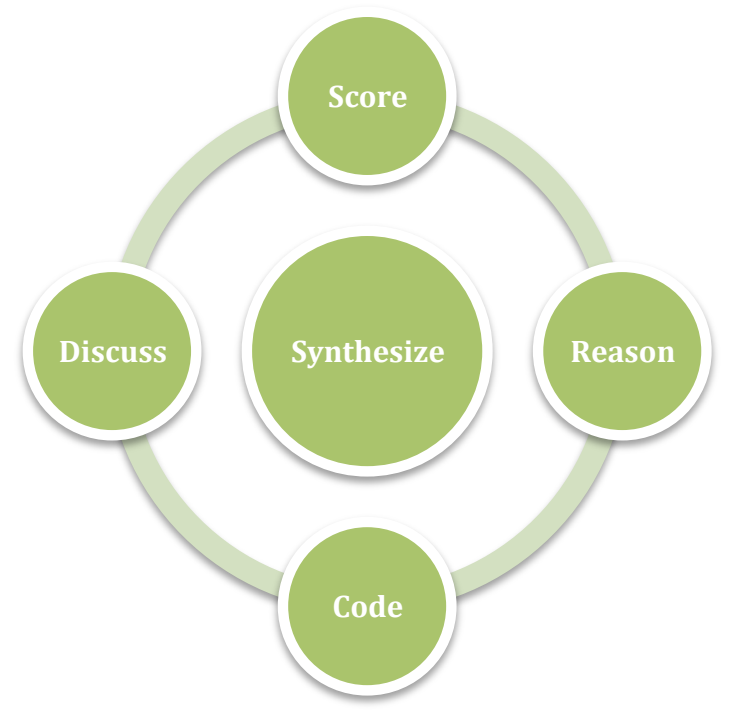

Figure 3. Capability assessment protocol

\begin{tabular}{l|l}
\hline Step & Description \\
\hline Score & $\begin{array}{l}\text { Each researcher evaluated and scored the } \\
\text { hypothesis statements (Table 4) for before and } \\
\text { after the implementation of the industrial analytics } \\
\text { architecture. }\end{array}$ \\
\hline Reason & $\begin{array}{l}\text { For each score asserted, the researcher was } \\
\text { required to rationalize their decision using a textual } \\
\text { description. }\end{array}$ \\
\hline Code & $\begin{array}{l}\text { In addition to a textual description, the researcher } \\
\text { was also required to explicitly label the } \\
\text { architecture diagram to illustrate where they } \\
\text { envisaged the capability improvement. }\end{array}$ \\
\hline Discuss & $\begin{array}{l}\text { After scoring, reasoning and coding all } \\
\text { components in the model, the researcher presented } \\
\text { their assertions, and these were discussed and } \\
\text { evaluated by the group. }\end{array}$ \\
\hline Synthesize & $\begin{array}{l}\text { Finally, the individual assessments were } \\
\text { synthesized during group discussions to form the } \\
\text { final capability levels for before and after } \\
\text { implementation. This unified capability data is } \\
\text { presented and discussed in the following sections. }\end{array}$ \\
\hline
\end{tabular}

Table 6. Capability assessment protocol 
Figure 4 illustrates industrial analytics the synthesized capabilities across energy operations, before and after the implementation of the industrial analytics architecture. While the facility's traditional energy operations and systems were state-of-the-art, maturity assessments highlighted gaps between legacy and emerging technologies (e.g. data analytics). These gaps are assessed and discussed in the following sections.

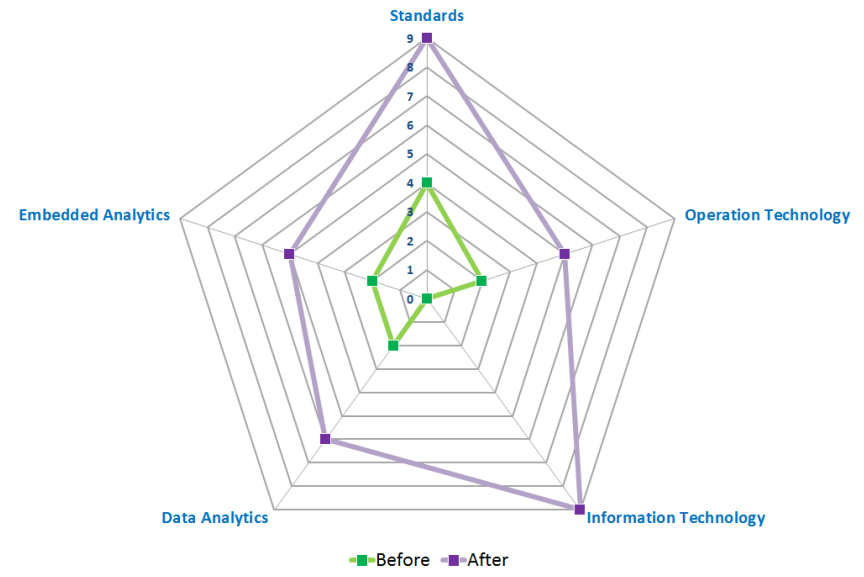

Figure 4. Comparison of industrial analytics capabilities

\subsection{Industrial Analytics Architecture}

Figure 6 illustrates the industrial analytics architecture for assessment (O'Donovan, Bruton, and O'Sullivan 2016). This architecture was originally implemented to promote consistent data flows between multidisciplinary teams, establish clear boundaries and responsibilities, and classify data streams to facilitate industrial analytics. These streams are labeled as batch and real-time. Batch streams are responsible for acquiring, cleaning and serving operational data to build data-driven models, while real-time streams leverage these models to monitor and inform real-world factory operations.
The codes overlaid (e.g. D1.2) on the industrial analytics architecture correspond to the IAMM's hypothesis statements (Table 4). These codes were added during the assessment protocol, which required those undertaking capability assessments to explicitly highlight and rationalize assertions. The final codes indicate capability improvements were evident across operational convergences (e.g. integration and interoperability) and analytics pipelines (e.g. building and deployment).

\subsection{Open Standards}

Positive changes in standards were evident across all areas excluding operational technology (Figure 5). Open standards were used (e.g. OLE Process Control) for building automation and control (Hong and Jianhua 2006), while no standards existed to support integration with cloud computing and analytics frameworks. This resulted in capability improvements relating to D1.2, D1.4 and D1.5. These improvements are discussed in Table 7.

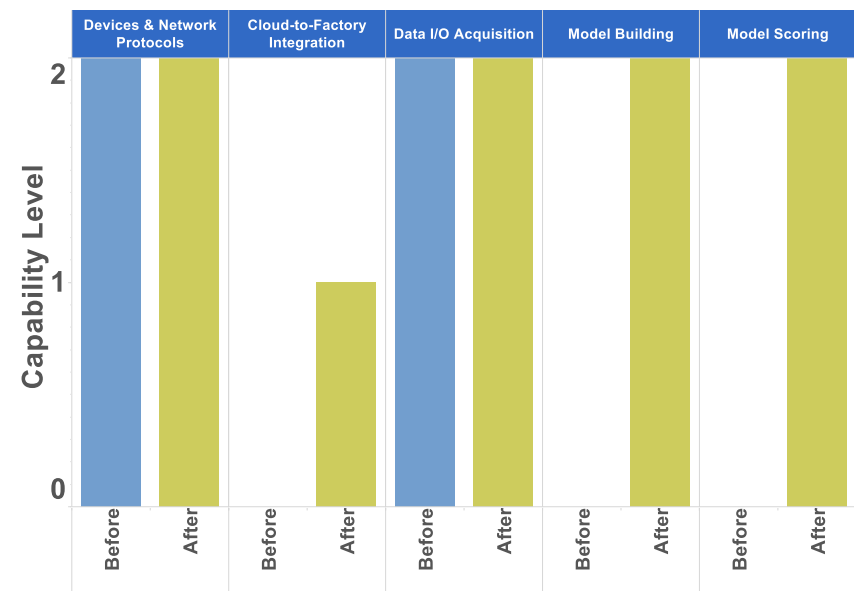

Figure 5. Open standards comparison 


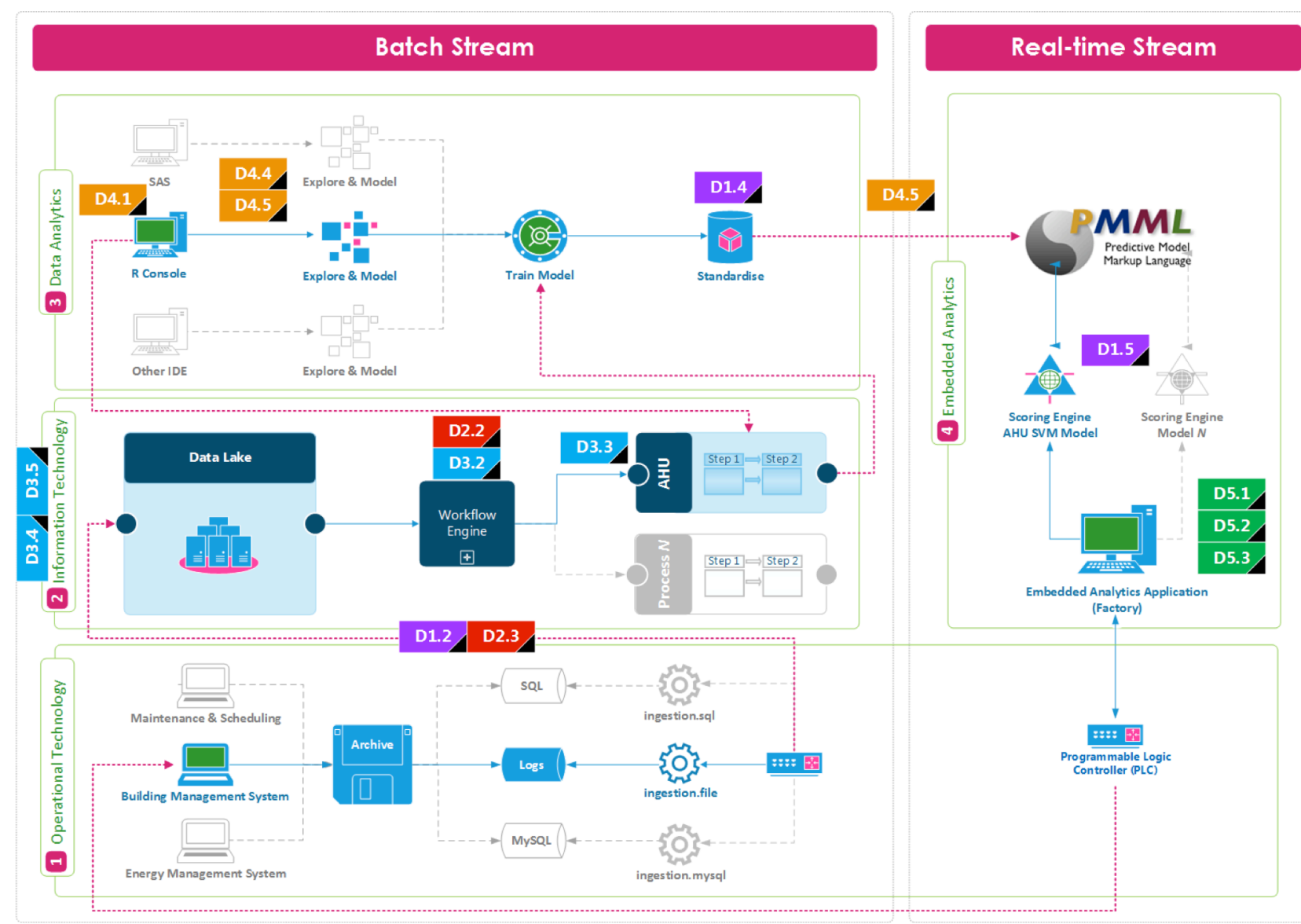

Figure 6. Coded analysis of lifecycle implementation (O’Donovan, Bruton, and O'Sullivan 2016)

\begin{tabular}{|c|c|}
\hline Component & Rationale \\
\hline $\begin{array}{l}\text { D1.1 } \\
\text { Devices \& } \\
\text { Network } \\
\text { Protocols }\end{array}$ & $\begin{array}{l}\text { Open standards are currently used for building } \\
\text { automation and control, while the industrial } \\
\text { analytics lifecycle implementation does not } \\
\text { target improvements at this level (Bacnet 2006; } \\
\text { Hong and Jianhua 2006; Kastner et al. 2005). } \\
\text { Therefore, no capability changes were expected } \\
\text { or recorded. }\end{array}$ \\
\hline $\begin{array}{l}\text { D1.2 } \\
\text { Cloud-to- } \\
\text { Factory } \\
\text { Integration }\end{array}$ & $\begin{array}{l}\text { The industrial analytics lifecycle implementation } \\
\text { (Figure 6) shows Hypertext Transfer Protocol } \\
\text { (HTTP) supporting factory-to-cloud integration } \\
\text { (Verivue 2008). An improved capability of } \\
\text { 'partial' was assigned given a proprietary } \\
\text { software library was used to support aspects of } \\
\text { integration. }\end{array}$ \\
\hline $\begin{array}{l}\text { D1.3 } \\
\text { Data I/O } \\
\text { Acquisition }\end{array}$ & $\begin{array}{l}\text { OLEDB, ODBC and standard I/O streams could } \\
\text { be used to access energy data from repositories } \\
\text { on the network. Similarly to device standards, } \\
\text { the implementation being assessed does not } \\
\text { target improvements for factory-level } \mathrm{I} / \mathrm{O} \text {, and } \\
\text { therefore, no capability changes were expected } \\
\text { or recorded. }\end{array}$ \\
\hline $\begin{array}{l}\text { D1.4 } \\
\text { Model }\end{array}$ & $\begin{array}{l}\text { Energy focused data-driven models were not } \\
\text { used before implementation. Therefore, no }\end{array}$ \\
\hline
\end{tabular}

\begin{tabular}{l|l} 
Building & $\begin{array}{l}\text { standards existed to support such models. The } \\
\text { industrial analytics lifecycle implementation } \\
\text { (Figure 6) utilizes Predictive Modeling Markup } \\
\text { Language (PMML) (Data Mining Group 2016)to } \\
\text { encode data-driven models. Full agreement with } \\
\text { the hypothesis statement was chosen given there } \\
\text { were no indications that PMML could not be } \\
\text { used as the basis to encode future models. }\end{array}$ \\
\hline $\begin{array}{l}\text { D1.5 } \\
\text { Scodel }\end{array}$ & $\begin{array}{l}\text { Given the lack of data-driven models, standards } \\
\text { to facilitate the scoring of energy data were not } \\
\text { necessary. The industrial analytics lifecycle } \\
\text { implementation (Figure 6) employs web } \\
\text { services to score data-driven models. These } \\
\text { services are initiated using HTTP requests, while } \\
\text { data exchanges are facilitated using JavaScript } \\
\text { Object Notation (JSON). Full agreement with the } \\
\text { hypothesis statement was deemed appropriate } \\
\text { given the complete use of standards from the } \\
\text { client-side. }\end{array}$ \\
\hline
\end{tabular}

Table 7 Open standards assessment 


\subsection{Operation Technology}

Positive changes in operation technology largely stemmed from data accessibility and availability of cloud computing technologies (Figure 7). This resulted in capability improvements relating to D2.2 and D2.3. These improvements are discussed in Table 8 .

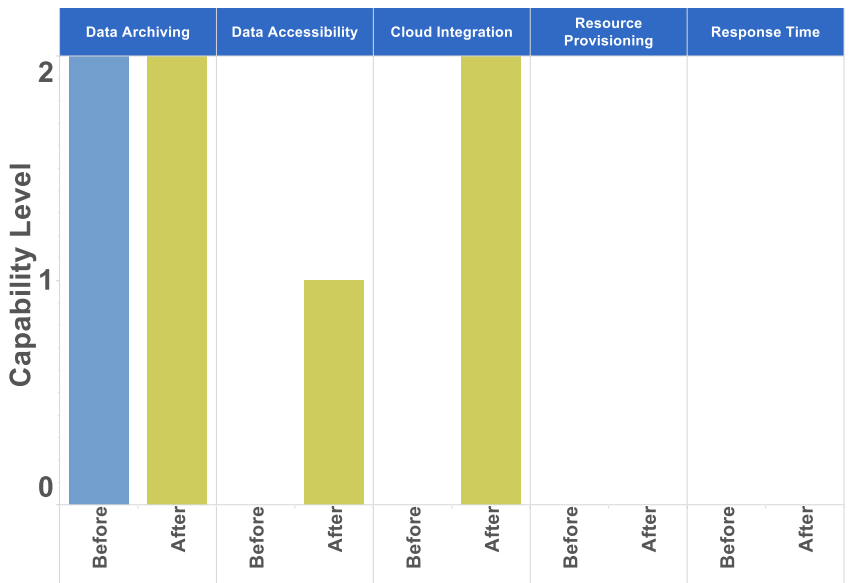

Figure 7. Operation technology comparison

\begin{tabular}{|c|c|}
\hline Component & Rationale \\
\hline $\begin{array}{l}\text { D2.1 } \\
\text { Data } \\
\text { Archiving }\end{array}$ & $\begin{array}{l}\text { Full maturity was applied given the Building } \\
\text { Management System (BMS) logs all energy- } \\
\text { related data points in the facility. }\end{array}$ \\
\hline $\begin{array}{l}\text { D2.2 } \\
\text { Data } \\
\text { Accessibility }\end{array}$ & $\begin{array}{l}\text { Existing energy data repositories exhibited } \\
\text { arbitrary naming conventions and were largely } \\
\text { inaccessible to networked users and processes. } \\
\text { Improvements were realized using a workflow } \\
\text { engine to contextualize data segments, while } \\
\text { processed data was accessible via HTTP. }\end{array}$ \\
\hline $\begin{array}{l}\text { D2.3 } \\
\text { Cloud } \\
\text { Integration }\end{array}$ & $\begin{array}{l}\text { Solely in the context of energy operations, auto- } \\
\text { scaling compute resources were implemented to } \\
\text { handle large-scale data processing and requests. } \\
\text { Given the ingestion and processing of all energy } \\
\text { data in the facility was previously demonstrated, } \\
\text { full maturity was assigned in this instance. }\end{array}$ \\
\hline $\begin{array}{l}\text { D2.4 } \\
\text { Resource } \\
\text { Provisioning }\end{array}$ & $\begin{array}{l}\text { No specific policies or processes existed to } \\
\text { support provisioning of tools or technologies for } \\
\text { industrial analytics. Given the technical nature of } \\
\text { the industrial lifecycle implementation, such } \\
\text { capabilities were not addressed or affected. }\end{array}$ \\
\hline $\begin{array}{l}\text { D2.5 } \\
\text { Response } \\
\text { Time }\end{array}$ & $\begin{array}{l}\text { General policies for provisioning resources were } \\
\text { not aligned with the quick turnaround times } \\
\text { specified in the hypothesis statement. Given the } \\
\text { technical nature of the industrial lifecycle } \\
\text { implementation, such capabilities were not } \\
\text { addressed or affected. }\end{array}$ \\
\hline
\end{tabular}

Table 8. Operation technology assessment

\subsection{Information Technology}

Given only minor convergences existed between operation and information technology for energy operations, many positive capability changes were observed (Figure 8). These improvements are discussed in Table 9.

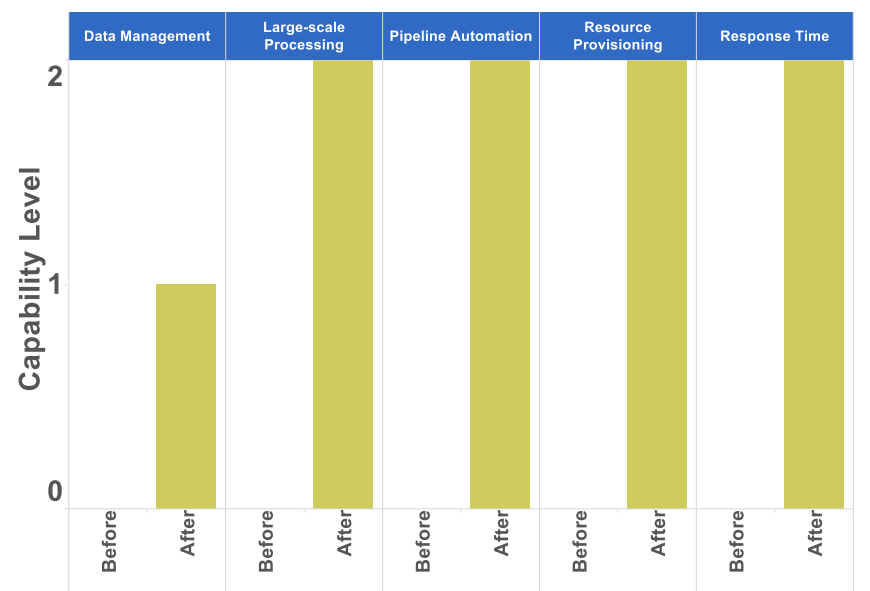

Figure 8. Information technology comparison

\begin{tabular}{l|l}
\hline Component & Rationale \\
\hline D3.1 & $\begin{array}{l}\text { While factory-level energy repositories used } \\
\text { arbitrary naming for data points, the } \\
\text { Management } \\
\text { implemented data lake comprised many tags that } \\
\text { described the origin and application of the data. } \\
\text { These tags were used to form a catalogue to } \\
\text { identify data sources for mapping and cleaning } \\
\text { operations. }\end{array}$ \\
\hline D3.2 & $\begin{array}{l}\text { Given the auto-scaling configuration used during } \\
\text { the industrial analytics lifecycle implementation, } \\
\text { data ingestion and workflow processes exist to } \\
\text { Processing }\end{array}$ \\
\hline $\begin{array}{l}\text { manage large datasets and interoperate with big } \\
\text { data tools. }\end{array}$ \\
Pipeline & $\begin{array}{l}\text { Formal implemented workflow processes } \\
\text { facilitated the turnkey cleaning and } \\
\text { transformation of energy data. This resulted in } \\
\text { analytics-ready data being served to end-users } \\
\text { and processes. }\end{array}$ \\
\hline D3.4 & $\begin{array}{l}\text { On-demand cloud computing enabled the } \\
\text { seamless provisioning of virtual resources to } \\
\text { support industrial analytics efforts. }\end{array}$ \\
\hline Provisioning & $\begin{array}{l}\text { Additional resources for existing infrastructure } \\
\text { were automated to reduce provisioning time. }\end{array}$ \\
\hline D3.5 & \\
Response &
\end{tabular}

Table 9. Information technology assessment

\subsection{Data Analytics}

Positive changes in data analytics were demonstrated by the use of statistical tools to apply analytical methods and deploy data-driven models (Figure 9). This resulted in capability improvements relating to D4.1, D4.3, D4.4 and D4.5. These improvements are discussed in Table 10. 


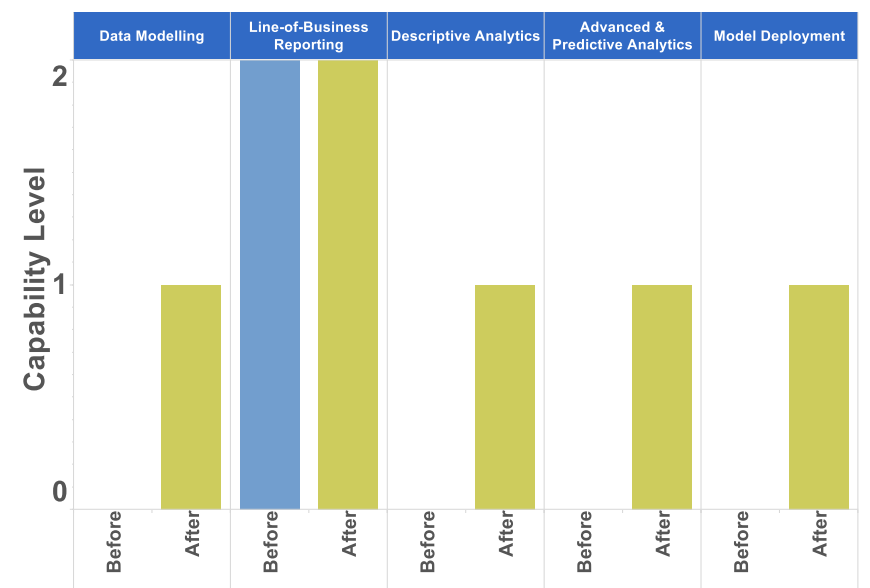

Figure 9. Data analytics comparison

\begin{tabular}{|c|c|}
\hline Component & Rationale \\
\hline $\begin{array}{l}\text { D4.1 } \\
\text { Data } \\
\text { Modelling }\end{array}$ & $\begin{array}{l}\text { Existing information systems were used to } \\
\text { display energy data and operations, with no } \\
\text { apparent application of statistical data analysis. } \\
\text { Post-implementation such activities were } \\
\text { demonstrated using R Studio and associated } \\
\text { software packages. }\end{array}$ \\
\hline $\begin{array}{l}\text { D4.2 } \\
\text { Line-of- } \\
\text { Business } \\
\text { Reporting }\end{array}$ & $\begin{array}{l}\text { Some aspects of energy operations demonstrated } \\
\text { ad hoc analysis using MS Excel and MS SQL. } \\
\text { These capabilities were not targeted or affected } \\
\text { after the lifecycle implementation. }\end{array}$ \\
\hline $\begin{array}{l}\text { D4.3 } \\
\text { Descriptive } \\
\text { Analytics }\end{array}$ & $\begin{array}{l}\text { The implementation demonstrated descriptive } \\
\text { analytics using RStudio to identify anomalies in } \\
\text { time-series trends for Air Handling Units } \\
\text { (AHU's) in the factory. These capabilities were } \\
\text { directly enabled by the accessibility of clean and } \\
\text { processed energy data from the workflow engine. }\end{array}$ \\
\hline $\begin{array}{l}\text { D4.4 } \\
\text { Advanced } \\
\text { Analytics }\end{array}$ & $\begin{array}{l}\text { The implementation demonstrated advanced } \\
\text { analytics capabilities by training a machine } \\
\text { learning model to automatically identify issues } \\
\text { with heating components in AHU's. These } \\
\text { capabilities were informed by findings from } \\
\text { previously mentioned descriptive analytics } \\
\text { efforts. }\end{array}$ \\
\hline $\begin{array}{l}\text { D4.5 } \\
\text { Model } \\
\text { Deployment }\end{array}$ & $\begin{array}{l}\text { The implementation facilitated the deployment } \\
\text { of PMML encoded data-driven models to } \\
\text { accessible cloud-based repositories. This enabled } \\
\text { model to collaborate with scoring components to } \\
\text { facilitate deployment in the factory. }\end{array}$ \\
\hline
\end{tabular}

Table 10. Data analytics assessment

\subsection{Embedded Analytics}

Positive changes in embedded analytics stemmed from the ability to operationalize analytics models informed by subject matters (Figure 10). This resulted in capability improvements relating to D5.1, D5.2, and D5.3. These improvements are discussed in Table 11.

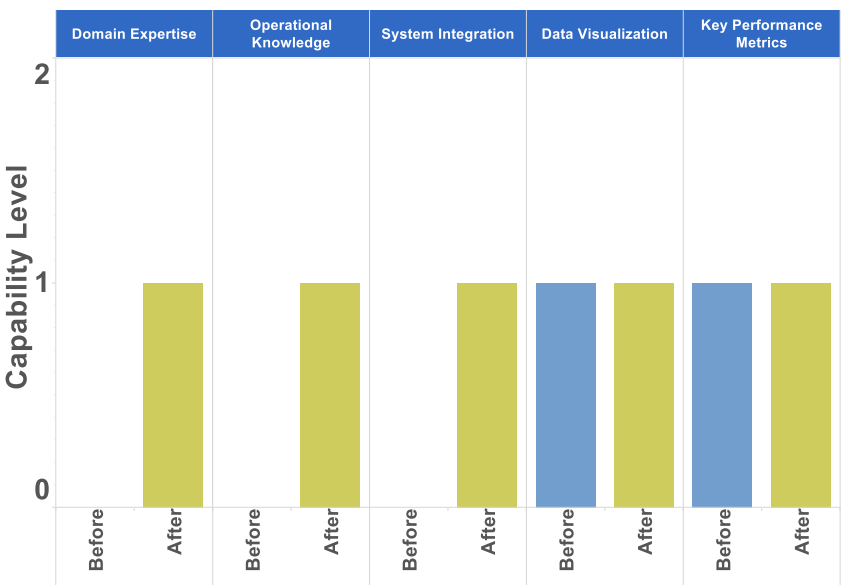

Figure 10. Embedded analytics comparison

\begin{tabular}{|c|c|}
\hline Component & Rationale \\
\hline $\begin{array}{l}\text { D5.1 } \\
\text { Domain } \\
\text { Expertise }\end{array}$ & $\begin{array}{l}\text { Incorporating subject matter expertise was } \\
\text { facilitated by the analytics lifecycle, where } \\
\text { knowledge relating to AHU diagnostics was to } \\
\text { guide the construction and deployment of a } \\
\text { diagnostics application. }\end{array}$ \\
\hline $\begin{array}{l}\text { D5.2 } \\
\text { Operational } \\
\text { Knowledge }\end{array}$ & $\begin{array}{l}\text { This particular capability was graded 'partial' } \\
\text { given expertise for industrial energy, utilities and } \\
\text { diagnostics were used to demonstrate the } \\
\text { analytics lifecycle implementation. }\end{array}$ \\
\hline $\begin{array}{l}\text { D5.3 } \\
\text { System } \\
\text { Integration }\end{array}$ & $\begin{array}{l}\text { The operationalization of data-driven models for } \\
\text { energy operations did not exist before the } \\
\text { implementation of the industrial analytics } \\
\text { lifecycle. The industrial analytics lifecycle } \\
\text { demonstrated the integration of factory-level } \\
\text { operations with analytics output via a diagnostic } \\
\text { application embedded in the facility. }\end{array}$ \\
\hline $\begin{array}{l}\text { D5.4 } \\
\text { Data } \\
\text { Visualization }\end{array}$ & $\begin{array}{l}\text { Different information systems were used in the } \\
\text { factory to present and explore energy data } \\
\text { recorded in the facility. The implementation did } \\
\text { not extend these capabilities, which resulted in } \\
\text { capabilities being unaffected. }\end{array}$ \\
\hline $\begin{array}{l}\text { D5.5 } \\
\text { Key } \\
\text { Performance } \\
\text { Metrics }\end{array}$ & $\begin{array}{l}\text { Internal metrics relating to energy consumption } \\
\text { are used to gauge performance. Given the } \\
\text { implementation did not enhance these } \\
\text { capabilities, maturity levels remained the same. }\end{array}$ \\
\hline
\end{tabular}

Table 11. Embedded analytics assessment

\section{Conclusions}

There are many challenges associated with developing industrial analytics capabilities. Some common challenges include managing heterogeneous technologies and platforms, forming multidisciplinary teams, and formalizing prescriptive approaches, to name a few. Such challenges are exacerbated further where no methods exist to measure current capability levels, and strategically identify areas for improvement (e.g. technical roadmap). Thus, this research considered the use of maturity models to classify and quantify industrial analytics capabilities. 
The industrial analytics maturity model (IAMM), which was developed during this research, was used to highlight capability improvements across energy operations after the execution of an industrial analytics initiative. These results showed positive improvements, but this was expected given energy operations had no analytics infrastructure before implementation. However, maturity assessments should not be considered isolated events, but rather a longitudinal process, where capability levels are continuously monitored, improved and compared. Such processes organically produce quantifiable benchmarks, which may be used to compare capabilities across departments and facilities. The IAMM provides a foundational framework for capability assessment, which researchers and practitioners may extend to meet specific requirements. Indeed, these refinements and extensions are necessary to improve the representation of the domain being assessed.

Future work will focus on the refinement and extension of the current model, as well as the development of an IAMM compliant cloud-based web and mobile application to support ongoing capability assessment and reporting.

\section{ACKNOWLEDGEMENT}

The authors would like to thank the Irish Research Council, DePuy Ireland for their funding of this research, which is being undertaken as part of the Enterprise Partnership Scheme (EPSPG/2013/578).

\section{REFERENCES}

Abdel-Fattah, Manal A. 2015. "Grounded Theory and Action Research as Pillars for Interpretive Information Systems Research: A Comparative Study." Egyptian Informatics Journal 16(3): 309-27. http://dx.doi.org/10.1016/j.eij.2015.07.002.

Ayca, Tarhan, Turetken Oktay, Ir Hajo, and A Reijers. 2016. "Business Process Maturity Models: A Systematic Literature Review." Information and Software Technology 75: 122-34. http://dx.doi.org/10.1016/j.infsof.2016.01.010.

Bacnet, How. 2006. "White Paper: BACnet vs . Lon - The War Is Over." : 1-3.

Becker, Jörg, Ralf Knackstedt, and Jens Pöppelbuß. 2009. "Developing Maturity Models for IT Management." Business \& Information Systems Engineering 1(3): 213-22.

De Bruin, Tonia, Ronald Freeze, Uday Kaulkarni, and Michael Rosemann. 2005. "Understanding the Main Phases of Developing a Maturity Assessment Model." Australasian Conference on Information Systems (ACIS): 8-19. http://eprints.qut.edu.au/25152/.

Chand, Sujeet, and Jim Davis. 2010. "What Is Smart Manufacturing ?" Time Magazine.
Data Mining Group. 2016. "PMML 4.3.” Data Mining Group. http://dmg.org/pmml/v43/GeneralStructure.html.

Davis, Jim et al. 2012. "Smart Manufacturing, Manufacturing Intelligence and Demand-Dynamic Performance." Computers \& Chemical Engineering 47: 145-56.

http://linkinghub.elsevier.com/retrieve/pii/S009813541 2002219 (January 10, 2014).

Dinter, Barbara. 2012. "The Maturing of a Business Intelligence Maturity Model." Proceedings of the Eighteenth Americas Conference on Informaiton Systems: 1-10.

Donovan, Peter O et al. 2015. "A Data Pipeline for PHM Data-Driven Analytics in Large-Scale Smart Manufacturing Facilities." Annual Conference of the Prognostics and Health Management Society (September): 367-76.

Fosso Wamba, Samuel et al. 2015. "How 'big Data' Can Make Big Impact: Findings from a Systematic Review and a Longitudinal Case Study." International Journal of Production Economics: 1-13. http://linkinghub.elsevier.com/retrieve/pii/S092552731 4004253.

Halper, Fern, and Krish Krishnan. 2014. "TDWI Big Data Maturity Model Guide.” RDWi Resarch 2013-2014: 120.

Hazen, Benjamin T., Christopher a. Boone, Jeremy D. Ezell, and L. Allison Jones-Farmer. 2014. "Data Quality for Data Science, Predictive Analytics, and Big Data in Supply Chain Management: An Introduction to the Problem and Suggestions for Research and Applications." International Journal of Production Economics 154: 72-80. http://linkinghub.elsevier.com/retrieve/pii/S092552731 4001339 (May 25, 2014).

Hong, $\mathrm{Xu}$, and Wang Jianhua. 2006. "Using Standard Components in Automation Industry: A Study on OPC Specification." Computer Standards \& Interfaces 28(4): 386-95.

http://linkinghub.elsevier.com/retrieve/pii/S092054890 5000814 (October 19, 2012).

IBM. 2016. "Big Data \& Analytics Maturity Model."

IDC. 2016. "CSC Big Data Maturity Tool."

Infotech. 2016. "Big Data Maturity Assessment Tool." https://www.infotech.com/research/ss/it-develop-apattern-based-big-data-strategy-to-accelerate-big-datavalue/it-big-data-maturity-assessment-tool.

Kastner, Wolfgang, Georg Neugschwandtner, Stefan Soucek, and H Michael Newman. 2005. "Communication Systems for Building Automation and Control." 93(6).

Knowledgent. 2016. "Big Data Maturity Assessment."

Koehler, Jana, Roland Woodtly, and Joerg Hofstetter. 2015. "An Impact-Oriented Maturity Model for IT-Based 
Case Management." Information Systems 47: 278-91. http://dx.doi.org/10.1016/j.is.2013.12.003.

Kohlegger, M., R. Maier, and S. Thalmann. 2009. "Understanding Maturity Models Results of a Structured Content Analysis." Proceedings of IKNOW '09 and ISEMANTICS '09 (September): 51-61. http://iwi.uibk.ac.at/download/downloads/Publikationen /KMM.pdf.

Kumar, Praveen, Bhawna Dhruv, Seema Rawat, and Vijay S Rathore. 2014. "Present and Future Access Methodologies of Big Data." International Journal of Advance Research in Science and Engineering 8354(3): 541-47.

Lahrmann, Gerrit, and Frederik Marx. 2010. "Systematization of Maturity Model Extensions." Lecture Notes in Computer Science (including subseries Lecture Notes in Artificial Intelligence and Lecture Notes in Bioinformatics) 6105 LNCS: 522-25.

Lahrmann, Gerrit, Frederik Marx, Robert Winter, and Felix Wortmann. 2011. "Business Intelligence Maturity Models : An Overview." 44th Hawaii International Conference on System Sciences: 1-12. http://ieeexplore.ieee.org/lpdocs/epic03/wrapper.htm?ar number $=5718882$.

Lee, Jay, Behrad Bagheri, and Hung-an Kao. 2015. "A Cyber-Physical Systems Architecture for Industry 4.0Based Manufacturing Systems." Manufacturing Letters 3(September 2015): 18-23. http://www.sciencedirect.com/science/article/pii/S2213 84631400025X (January 14, 2015).

Lee, Jay, Hung-An An Kao, and Shanhu Yang. 2014. "Service Innovation and Smart Analytics for Industry 4.0 and Big Data Environment." Procedia CIRP 16: 38.

http://www.sciencedirect.com/science/article/pii/S2212 827114000857 (July 14, 2014).

Lee, Jay, Edzel Lapira, Behrad Bagheri, and Hung-an Kao. 2013. "Recent Advances and Trends in Predictive Manufacturing Systems in Big Data Environment." Manufacturing Letters 1(1): 38-41. http://linkinghub.elsevier.com/retrieve/pii/S221384631 3000114 (January 10, 2014).

McKinsey. 2011. Big Data: The next Frontier for Innovation, Competition, and Productivity.

Mettler, Tobias. 2009. "A Design Science Research Perspective on Maturity Models in Information Systems." Universiteit St. Gallen, St. Gallen, Switzerland, Technical Report BE IWI/HNE/03 41(0). http://ehealth.iwi.unisg.ch/fileadmin/hne/downloads/20 090512_Maturity_Model_Design.pdf.

Ngai, E. W T, D. C K Chau, J. K L Poon, and C. K M To. 2013. "Energy and Utility Management Maturity Model for Sustainable Manufacturing Process." International Journal of Production Economics 146(2): 453-64.

O'Donovan, Peter, Ken Bruton, and Dominic T.J. O’Sullivan. 2016. "Case Study: The Implementation of a Data-Driven Industrial Analytics Methodology and Platform for Smart Manufacturing." International Journal of Prognostics and Health Management 7: 122.

Ofner, Martin, Boris Otto, and Hubert Österle. 2015. “A Maturity Model for Enterprise Data Quality Management." Enterprise Modelling and Information Systesms Architectures 8(November).

Oliva, Fábio Lotti. 2016. "A Maturity Model for Enterprise Risk Management." International Journal of Production Economics 173: 66-79. http://linkinghub.elsevier.com/retrieve/pii/S092552731 5005320 .

Philip Chen, C.L., and Chun-Yang Zhang. 2014. "DataIntensive Applications, Challenges, Techniques and Technologies: A Survey on Big Data." Information Sciences 275: 314-47. http://linkinghub.elsevier.com/retrieve/pii/S002002551 4000346 (March 20, 2014).

Poeppelbuss, Jens, Bjoern Niehaves, Alexander Simons, and Jörg Becker. 2011. "Maturity Models in Information Systems Research: Literature Search and Analysis." Communications of the Association for Information Systems 29(1): 506-32.

Potter, Dan. 2014. "Industrial Analytics Powered by the Internet of Things Industrial." (2).

Radcliffe, By John. 2014. "Leverage a Big Data Maturity Model to Build Your Big Data Roadmap." Radcliffe Advisory Services Ltd (January). www.radcliffeadvisory.com.

Rajterič, I Hribar. 2010. "Overview of Business Intelligence Maturity Models." Management: Journal of Contemporary Management ... 15: 47-67. http://hrcak.srce.hr/index.php?show=clanak\&id_clanak jezik=81745.

Torrecilla-Salinas, C. J., J. Sedeño, M. J. Escalona, and M. Mejías. 2016. "Agile, Web Engineering and Capability Maturity Model Integration: A Systematic Literature Review." Information and Software Technology 71: 92-107.

Vera-baquero, Alejandro, Ricardo Colomo-palacios, and Owen Molloy. 2014. "Towards a Process to Guide Big Data Based Decision Support Systems for Business Processes." In Conference on ENTERprise Information Systems Towards,

Verivue, Steve Vinoski. 2008. "RPC and REST."

De Villiers, M. R. 2005. "Three Approaches as Pillars for Interpretive Information Systems Research: Development Research, Action Research and Grounded Theory." South African Institute of Computer Scientists and Information Technologists: 111-20.

Wright, Paul. 2014. "Cyber-Physical Product Manufacturing." Manufacturing Letters 2(2): 49-53. http://www.sciencedirect.com/science/article/pii/S2213 846313000187. 